e-ISSN: $1984-4255 \quad$ ARGUMENTOS

D0I: $10.36517 /$ Argumentos.25.10

\title{
Utopia, história e profecia: o joaquimismo como filosofia do Brasil
}

\author{
Utopia, history and prophecy: \\ the joaquimism as philosophy for Brazil
}

\author{
Noeli Dutra Rossatto \\ https://orcid.org/0000-0003-4176-574X - E-mail: rossatto.dutra@gmail.com
}

\begin{abstract}
RESUMO
O texto assume que a concepção de história das vertentes utópica e profético-milenarista são constitutivas não só do mito fundador do Estado brasileiro, senão que também de nosso pensamento filosófico mais autêntico; e que, em suas origens, encontramos a obra do abade Joaquim de Fiore (1135-1202). Em um primeiro momento, procuramos mostrar que uma das expressões da vertente utópica em nossa cultura provém das populares Festas do Império do Divino Espírito Santo de tradição luso-brasileira que tem raízes no joaquimismo medieval. A vertente profético-milenarista, por sua vez, entronca na obra do jesuíta Antônio Vieira (16081679) e se consolida mediante a absorção da herança utópica do joaquimismo, mesclada com elementos apocalípticos e sebastianistas. Por fim, tomamos alguns passos do romance $A$ Pedra do Reino, de Ariano Suassuna (1927-2014), que, a nosso ver, articulam o núcleo principal da vertente utópica com a teoria do Quinto Império e o milenarismo.
\end{abstract}

Palavras-chave: Profecia. Utopia. Quinto Império. Joaquim de Fiore. Antônio Vieira.

\begin{abstract}
The text assumes that the conception of history from the utopian and prophetic-millenarian strands are constitutive not only of the founding myth of the Brazilian State, but also of our most authentic philosophical thought; and that, in its origins, we find the work of Abbot Joachim of Fiore (1135-1202). At first, we show that one of the expressions of the utopian aspect in our
\end{abstract}


culture comes from the popular Festivities of the Empire of the Holy Spirit of Luso-Brazilian tradition that roots in medieval Joachimism. The prophetic-millenarian aspect, in turn, is part of the work of the Jesuit Antonio Vieira (1608-1679) and consolidated through the absorption of the utopian heritage of the Joaquimism, complemented by Apocalyptic and Sebastianian elements. Finally, we take a few steps from the novel A Pedra do Reino, by Ariano Suassuna (1927-2014), with, in our view, articulate the main core of the utopian dimension with the theory of the Fifth Empire and the millenarianism.

Keywords: Prophecy. Utopia. Fifth Empire. Joachim of Fiore. Antonio Vieira.

\section{Posição do problema}

Muitas coisas estão sendo veiculadas e discutidas nas redes sociais a respeito de que a obra de Joaquim Fiore (1135-1202) - ou a de seus seguidores -, se constitui em uma das fontes heréticas das ideias produzidas no Brasil desde a época de sua descoberta e colonização. No entanto, pouco se tem feito no sentido de precisar as verdadeiras origens e o real impacto desta filosofia em nossa cultura. Alguns argumentam, não sem razão, que o joaquimismo, como uma vertente heterodoxa, herética e dissidente, esteve presente não só no imaginário dos descobridores da América, como é o caso do navegador Cristóvão Colombo (1992), que tenta ler em chave profética a conjuntura histórico-política de seu tempo, senão que também fará parte da formação e do credo de muitos franciscanos e jesuítas que se lançaram confiantes na aventura espiritual do Novo Mundo (BATAILLON, 1959; PHELAN, 1970; FERNANDES, 2007). Teríamos, assim, no primeiro momento da colonização, um joaquimismo de corte renascentista, profético, apocalíptico e utópico, que veio para as terras brasileiras e que não é muito diferente daquele que está na raiz da própria edição veneziana das três obras principais do abade, entre 1519 e 1527, a saber: a Concordia Novi ac Veteris Testamenti, o Psalterium decem chordarum e a Expositio in Apocalipsim. Teríamos também um joaquimismo que busca construir uma utopia na América; e que, para tanto, defenderá a vida e cultura dos indígenas americanos, o que, não raras vezes e consequentemente, estará em franca oposição aos interesses econômicos, à política colonial e à própria orientação eclesiástica dominantes.

De modo mais palpável, no Brasil atual, estudos de diferentes áreas do conhecimento darão especial destaque ao joaquimismo profético. É o caso do importante livro da filósofa Marilena Chauí (2000, p. 57-92), Brasil. Mito fundador e sociedade autoritária, que situa a concepção de história profético-milenarista do joaquimismo entre as quatro constituintes do mito fundador do Estado brasileiro. Segundo a autora, esta vertente foi assimilada pelas camadas populares ao longo da História do Brasil em contraposição ao providencialismo histórico do De civitate Dei de Agostinho de Hipona, incorporado pela ortodoxia eclesiástica e pelas elites coloniais dominantes. A visão de história profético-milenarista estaria presente em significativos movimentos de resistência popular que marcaram a passagem da monarquia para a república no final do século XIX e início do século XX, entre eles, a Guerra de Canudos (1893-1897), na Bahia; a Guerra do Contestado (1912-16), na divisa entre Santa Catarina e Paraná; e o Movimento dos Monges Barbudos (1935-38) no Rio Grande do Sul (HUJAWA, 2008; FILATOW, 2002).

Ao lado deste joaquimismo de corte profético-milenarista com elementos do messianismo e do sebastianismo luso-brasileiro, destacaremos outra tendência de caráter mais utópico, celebrado pelas populares Festas do Império do Divino Espírito Santo de tradição luso- 
-brasileira. A propósito dos resquícios deste imaginário utópico, recentemente o sociólogo José de Souza Martins (2009), em Fronteira. A degradação do outro nos confins do humano, registra que alguns focos de migrações do nordeste brasileiro para a região amazônica se dizem guiados por profecias derivadas da doutrina joaquimita, em que vislumbram um lugar mítico, depois da travessia do grande rio, denominado Paraíso do Divino.

Seguremos com a hipótese geral de que as raízes desse joaquimismo profético-utópico de corte luso-brasileiro estão assentadas nas tradicionais Festas do Império do Divino Espírito Santo, que é uma espécie de alegoria do terceiro estado espiritual; e que, por sua vez, o joaquimismo profético-milenarista ganhará impulso em nosso meio acadêmico a partir do horizonte delineado pela obra profética do Padre Antônio Vieira. A propósito, ousamos afirmar que a concepção de história do jesuíta não é apenas a mais importante do cristianismo pós-medieval, senão que se destina a substituir as filosofias da história e a própria hermenêutica dos textos bíblicos de Agostinho e de Joaquim de Fiore: a primeira em crise depois da passagem do primeiro milênio cristão; a segunda, precisando ser retocada após a descoberta do Novo Mundo.

Por fim, tomaremos o romance $A$ pedra do reino, de Ariano Suassuna, como exemplo de que esta mescla do joaquimismo utópico e profético com o pensamento vieiriano ainda permanece viva nas nossas narrativas de ficção literária mais recentes.

\section{Utopia e Império do Divino}

Vários estudos dão por certo que a origem das Festas do Império do Divino está vinculada à obra de Joaquim de Fiore, seja ela autêntica ou apócrifa. Os mesmos estudos ratificam o suposto de que a ponte entre a obra do abade calabrês, a devoção ao Espírito Santo e a coroa portuguesa foi construída desde o início pelos frades franciscanos. E mesmo que outros venham ponderar que as Festas do Divino são bem mais antigas que a própria coroa portuguesa, já não se discute a respeito de que elas foram impulsionadas pelo rei de Portugal Dom Dinis I (1279-1325), e sua esposa, a rainha Isabel (1269-1336), a Santa (FRANCO; MOURÃO, 2005, p. 105; ROSSATTO, 2003). Aliás, será a própria rainha Santa que irá instituir, em 1292, a Confraria do Espírito Santo de Alenquer em Portugal; e é da Vila de Alenquer, então senhorio da rainha, que sairá o franciscanismo espiritual que se expandirá em terras lusitanas.

Tal explicação adquire maior consistência e rigor na medida em que traz à luz, em um segundo momento, outros aspectos não menos relevantes. A rainha Isabel, filha de Pedro III de Aragão e Constança de Hohenstaufen (ou Constança II da Sicília), foi educada em Barcelona, então capital do Reino de Aragão, que era o lugar para onde acorreram, junto com os espirituais franciscanos, as doutrinas sobre o Espírito Santo. É bem provável que foi em Barcelona - ou mesmo Lisboa - que a Rainha Isabel teve contato com as ideias de um conhecido joaquimita, o médico e filósofo Arnaldo de Vilanova (1238-1316). Por aqueles dias, o filósofo catalão, que na época fugia das perseguições eclesiásticas, foi acolhido na corte aragonesa, transformando-se em diplomata e chanceler dos dois irmãos da rainha Isabel, Afonso III (1285-1291) e Jaime II de Aragão (1267-1327), que também reinou na Sicília.

Tal nexo permite explicar de forma bastante consistente um dos principais motivos da aliança inicial entre o Império e o Divino. A proposta dos espirituais franciscanos e das confrarias do Espírito Santo, baseada no ideal da pobreza evangélica, irá ao encontro dos interesses das nascentes monarquias europeias, sedentas pelas riquezas eclesiásticas. Ao lado disso, a pregação profética do advento de uma nova era, em que o clero daria lugar aos novos "homens espirituais" (viri spiritualis), não só viria ao encontro das mesmas monarquias, senão que também 
das camadas populares excluídas da produção do sagrado em mãos de uma ordem sacerdotal. Soma-se a isso a promessa de reconstituição de um Império Universal terreno, proveniente do próprio ideário do franciscanismo espiritual, e que reaviva o antigo sonho do cristianismo primitivo que, em terras portuguesas, ganhará forma com a doutrina messiânica do sebastianismo e do Quinto Império.

O culto e as festas em louvor ao Império do Divino Espírito Santo logo vão se transformar em devoção popular e se difundir rapidamente por todo território português. Seu apogeu será entre o século XIV e a primeira metade do XVI, coincidindo com o auge da expansão marítima portuguesa, o que não deixa dúvidas a respeito da íntima ligação com o Brasil. Devido a isso, a devoção popular ao Espírito Santo terá reflexos diretos na própria política do Estado português, sendo mesclada posteriormente com as doutrinas do Quinto Império e do sebastianismo.

Ao lado desta rica e complexa problemática de fundo, que com certeza carece em muitos aspectos de maior aprofundamento, nossa proposta se limita a examinar pontualmente a relação entre as Festas do Império do Divino e a doutrina de Joaquim de Fiore que se transladou para nosso território.

Em especial, perguntamos: seriam estas festividades uma verdadeira celebração da utopia do terceiro estado joaquimita?

É preciso destacar, de saída, que, tal como a doutrina do abade, a Festa do Império do Divino celebra o momento da passagem do estado filial, que fora protagonizado por Jesus e a ordem dos clérigos, para o estado espiritual a ser conduzido por uma nova ordem monástica. Uma das provas da filiação ao joaquimismo é que a liturgia em homenagem ao Espírito Santo nem sempre foi bem acolhida nos círculos eclesiásticos; e um dos aspectos polêmicos dessas celebrações, que sempre esteve na mira da ortodoxia, foi justamente o postulado de que, no terceiro estado do mundo, protagonizado pelos monges (ordo monachorum), seria dispensável a participação dos clérigos (ordo clericorum) (VERARDI, 1992).

Ainda hoje temos os resquícios da aplicação deste postulado, reforçado pela hermenêutica dos franciscanos espirituais. Como bem observam alguns estudiosos, a direção e a organização dos cultos e dos festejos do Império do Divino estão a cargo dos leigos, escapando totalmente ao controle eclesiástico. A respeito disso, registra o historiador e diretor do Núcleo de Estudos Açorianos da Universidade Federal de Santa Catarina (UFSC - Brasil), Joi Cletison (2003): "O cantador da Folia do Divino, no comando do Culto ao Divino, nos remete ao Abade Joaquim de Fiore, criador da doutrina sobre o Espírito Santo que diz: 'A terceira era, era plena do Espírito Santo, será a era dos monges e não mais dos sacerdotes"'. Com razão, ele sugere que o verdadeiro motivo pelo qual os festejos passaram a ser o alvo de perseguição a partir do século XVI, não foi o caráter pagão, como muitos alegaram, senão a exclusão do clero de tais festejos.

Em complementação, agregamos uma prova de que a teoria dos três estados, com acento na utopia da nova era espiritual, ainda se mantém intacta no imaginário popular brasileiro, vinculado a tais festejos. Vejamos, na sequência, parte de uma entrevista com um dos organizadores da Festa do Divino de Pirenópolis (Goiás), uma das mais famosas cidades do Brasil colonial, onde anualmente ocorrem tais celebrações. Lemos, na entrevista, recolhida pelo antropólogo Carlos Rodrigues Brandão (1978, p. 65), em seu livro O Divino, o santo e a senhora:

Ainda na Idade Média teria aparecido em Portugal um monge considerado como um santo. Depois de longos anos de retiro no deserto, foi-lhe revelada a vinda próxima de uma Nova Era de relações entre os homens sobre a Terra: a época do Espírito Santo. A humanidade teria já ultrapassado a época do Pai (o Antigo Testamento) e, ao seu tempo, terminava o seu trânsito por sobre a época do Filho (Novo Testamento). Estaria para chegar ao mundo 
a época final, a do Espírito Santo, marcada pelo advento de uma implantação definitiva da paz, do amor, da bondade entre todos os homens do mundo. [...] $\mathrm{O}$ monge voltou às cidades e procurou difundir a revelação recebida, tida imediatamente como revolucionária pelas autoridades eclesiásticas do seu tempo. Suas ideias proféticas conquistaram inúmeros adeptos, logo perseguidos por uma igreja oficial, ao mesmo tempo medieval e fechada. [...]. Inúmeros adeptos da nova crença migraram para o Brasil, logo depois de sua colonização.

Apesar de não referir expressamente o nome de Joaquim de Fiore, temos alguns indícios que não deixam dúvidas quanto a se tratar do abade cisterciense e de sua filosofia. $\mathrm{O}$ cenário descrito é medieval e o personagem principal é um monge. Há uma clara referência ao conhecido episódio da vida do abade que, quando ainda jovem (iuvenculus), vestira o hábito monástico - talvez eremita -, e empreendera uma longa viagem à Terra Santa (BITTONTI; OLIVERIO, 1998, p. 20; POTESTÀ, 1999, p. 5). De resto, mantém fidelidade ao que a lenda acrescentou a respeito deste episódio biográfico, quando acresce que, em seu "retiro no deserto", o jovem monge recebera uma "revelação" do Espírito Santo, mediante a qual compreendera a verdade que resultava da "concórdia" entre os dois testamentos, a qual daria origem ao seu método de interpretação das escrituras. Além disso, a alegada "revelação de uma Nova Era de relação entre os homens sobre a Terra", não foge dos pressupostos firmados pela autêntica vertente joaquimita que anuncia um novo estado espiritual, também conhecido como "Nova era" ou "época do Espírito". Porém, o que mais impressiona é a menção à teoria dos três estados (status) do mundo, corretamente citada como a "época do Pai", atribuída ao Antigo Testamento, a "época do Filho", atribuída ao Novo Testamento, e a vindoura "época do Espírito", associada ao período de paz, de amor e de bondade, prometido para o estado espiritual.

De acordo com isso, não é difícil concluir que os cultos e as festas do Divino Espírito Santo de tradição luso-brasileira são a mais viva e atual celebração da utopia joaquimita do terceiro estado espiritual que, aos poucos, se fundiu com o milenarismo e a filosofia política do Quinto Império.

Além disso, de especial destaque nos festejos é o personagem do Menino-Imperador, que simboliza a humanidade espiritualmente renovada do terceiro estado. Na tradição mais antiga, temos a coroação com três coroas, em que o protagonismo é assumido pelo MeninoImperador, ladeado por um rei jovem e outro ancião, em uma clara alusão ao que consta numa conhecida passagem da Concordia ac Veteris et Novus Testamenti (1964b, f. 112a), que diz a respeito dos três estados: "Primus senum, secundus iuvenum, tertius puerorum" (O primeiro é dos anciãos, o segundo dos jovens e o terceiro das crianças). Temos aí uma das características marcantes da utopia joaquimita, em que, no terceiro estado, as crianças governarão o mundo, inaugurando a nova era de paz, de liberdade e de caridade. Conforme bem observa Ernane Vianna (2000), em um artigo do jornal Folha de São Paulo: "Nas Festas do Divino, o impossível se torna realidade: as crianças governam o mundo, e as prisões e o trabalho são abolidos". Talvez seja o mesmo personagem do Menino-Imperador que reaparecerá na Guerra do Contestado com a figura do Joaquim-Menino, uma criança visionária que, com o término da guerra, deveria assumir o comando das Cidades Santas (AURAS, 2001, p. 81; SERPA, 1991, p. 47). E no mesmo sentido, só que acentuando o tom sebastianista, descreve Martins (2009, p. 165):"No Contestado, era preciso morrer para renascer no exército divino de São Sebastião; os velhos deveriam se tornar jovens, a sabedoria e o poder estavam com as crianças".

Ao lado dos símbolos normalmente atribuídos ao Espírito Santo, também cabe destacar, em segundo plano, que a tradicional bandeira do Divino, como estandarte principal levado nas procissões, geralmente está estampada em vermelho com uma pomba branca de asas abertas no centro. É significativo notar o uso da cor vermelha tanto no estandarte do Divino como nas 
vestimentas de seus protagonistas, pois esta cor está associada pela iconografia joaquimita ao estado espiritual, diferenciando-se do azul do estado filial e do verde do estado paterno (BITTONTI; OLIVERIO, 1999, p. 58-59).

Com isso, acreditamos ter mostrado a estreita vinculação entre as Festas do Império do Divino e o pensamento e a simbologia joaquimitas. Não obstante, é preciso destacar que, por meio desta liturgia festiva, temos a celebração de uma utopia genuinamente brasileira. Na sequência, mostraremos como, de algum modo, o pensamento joaquimita será retomado pela obra profética do Padre Antônio Vieira, marcando outro momento da recepção dessas ideias na nossa cultura filosófica.

\section{Quinto Império, profecia e milenarismo}

Vivendo no Brasil colonial em um período em que Portugal estava sob o domínio espanhol, Padre Antônio Vieira (1608-1679), o mais célebre pregador português de seu tempo, entende que Dom João IV de Bragança, morto em 1656, seria o restaurador da pátria. Com isso, ele reinterpretava o prognóstico do misterioso Rei Encoberto que, segundo as trovas do sapateiro Gonçalo Eanes Bandarra (1500-1556), se aplicava ao retorno do Rei Dom Sebastião, desaparecido em 1578, na Batalha de Alcáser-Quibir, no Marrocos. E além disso, na reinterpretação de Vieira, durante o Quinto Império, já em curso para ele, o poder seria exercido pelo Rei de Portugal e pelo papa, a lgreja de Cristo entraria em seu último estágio de perfeição, Jerusalém seria restaurada, os infiéis seriam convertidos e não teríamos mais guerras.

Consideraremos quatro principais escritos da obra profética do Padre Vieira: Esperanças de Portugal (1659), História do futuro (1663-65), Defesa perante o tribunal do Santo Ofício (1668) e Clavis Prophetarum (1670-77).

Não pretendemos afirmar que Vieira tenha bebido diretamente nos textos autênticos de Joaquim de Fiore, pois, ao que tudo indica, os traços proféticos, apocalípticos e milenaristas por ele incorporados em seus escritos se derivam de diferentes fontes, entre as quais algumas delas são joaquimitas e outras não (DE MARTINI; ROSSATTO, 2011). É verdade que Vieira recorre frequentemente à autoridade do venerável Abade Joaquim, na qual se apoia e inspira; e também demonstra conhecer a edição veneziana de suas três principais obras (VIEIRA, 1957, t. 2, p. 224). Porém, não podemos desconsiderar que ele também considerava como obra do abade o apócrifo Vaticínios ou profecias do abade Joaquim e de Anselmo Marsicani, editado conjuntamente com uma Vita de Joaquim, consultado durante sua estadia em Roma. Além do mais, as profecias atribuídas popularmente ao abade de Fiore já estavam diluídas e acrescidas no fértil imaginário luso-brasileiro do período das grandes navegações, da descoberta do Novo Mundo e da colonização do Brasil.

Destacamos, para fins de análise, três aspectos principais da vertente profético-milenarista que entra na cultura brasileira, permanecendo até nossos dias, e que tem no Padre Vieira a figura mais proeminente. São eles: a divisão do tempo em três eras, o embate final entre Cristo e o Anticristo e a era messiânica do segundo advento de Cristo, com a instalação de um reino de mil anos de felicidade (CHAUÍ, 2000, p. 88).

De qualquer modo que se tome em Vieira, tanto a compreensão dos três estados, como o messianismo e o milenarismo, não são um produto genuinamente joaquimita em sua concepção e em seu resultado. A divisão por três estados, na proposta do jesuíta, apesar de guardar certa similaridade com a estrutura escatológica do abade cisterciense, e a própria terminologia nos leva a pensar assim, não se aplica ao Reino do Espírito, mas apenas à subdivisão interna do 
Reino de Cristo (DE MARTINI; ROSSATTO, 2011). Neste sentido é que, na Defesa perante o tribunal do Santo Ofício, consta a seguinte divisão do terceiro estado, como: 1) o Império de Cristo Incoado - de Cristo a Constantino; 2) o Império de Cristo Imperfeito - de Constantino ao tempo de Vieira; e 3) o Império de Cristo completo e consumado - correspondente ao futuro Quinto Império (VIEIRA, 1957, t. 2, p. 271). Com base nesta tripartição do Império de Cristo por Vieira, temos de conceder que sua escatologia não tem como horizonte uma nova era espiritual, mas se limita a uma reformulação interna do Reino de Cristo, de modo a subdividi-lo em três estados.

De outro modo, o terceiro estado joaquimita não comporta um messianismo nos mesmos termos em que geralmente se atribui à espera de uma segunda vinda do Messias, na figura de um novo Salvador (D. Sebastião, D. João IV, entre outros), e em cumprimento às promessas apocalípticas. Tampouco podemos dizer que há um milenarismo stricto sensu, pois, na leitura que Joaquim faz do Apocalipse, seu cumprimento, com a abertura dos sete selos e a realização dos prognósticos previstos, não ultrapassa as últimas gerações do século XIII. Depois disso, a espera está depositada nas figuras espirituais do terceiro estado do mundo, regidas pelo Evangelho eterno.

Na distinção introduzida por Vieira, a terceira fase do Império de Cristo se realiza no período referente ao Quinto Império, sendo que o poder seria exercido pelo rei de Portugal e pelo papa. Nesta fase, a Igreja de Cristo entraria no seu último estágio de perfeição, Jerusalém seria restaurada, o mal desapareceria por um tempo, os infiéis seriam convertidos e não haveria mais guerra. Dando sequência a quatro impérios anteriores, a saber: o Assírio, o Persa, o Grego e o Romano, o Quinto Império, com sede em Lisboa, inauguraria um período de paz universal. $O$ que há de comum entre Vieira e Joaquim de Fiore, e que é diferente da concepção agostiniana da história, posteriormente assumida pela escolástica tomista, é que a revelação divina continuaria a ocorrer no interior da história humana e os tipos históricos vindouros, bons ou maus, fazem parte integrante do projeto de salvação.

No entanto, não podemos deixar de registrar que, na Clavis Prophetarum, Vieira revê a ideia de Quinto Império que, na História do futuro e na Defesa perante o Tribunal do Santo Ofício, tinha um caráter marcadamente nacionalista. Agora o Quinto Império expressará a promessa de realização do sonho utópico de universalidade do cristianismo, alcançando seu ponto álgido com o estabelecimento de uma era ecumênica de paz, justiça e fraternidade. É neste ponto que alguns estudiosos irão aproximar o jesuíta com a utopia do terceiro estado espiritual do joaquimismo (ESPÍRITO SANTO, 2009; FRANCO, 2015).

Neste mesmo sentido, temos a presença de duas figuras proeminentes na arquitetura escatológica de Antônio Vieira: a do Pastor angélico e a do Novo guia espiritual (VIEIRA, 1957, t. 2 , p. 268). Estas figuras, incomuns entre os jesuítas, que provavelmente foram decorrem doo contato com algumas fontes franciscanas (DE MARTINI; ROSSATTO, 2011), se encontram em uma passagem da Concórdia de Joaquim (1964b, f. 60), em que consta o seguinte prognóstico:

Quando, então, tiver início a quadragésima segunda geração da igreja [...], ascenderá da Babilônia o Novo guia (dux novus), o Pontífice universal da Nova Jerusalém [...], do qual está escrito no Apocalipse (Ap 7,2): 'vi um anjo subindo do nascer do sol com o selo de Deus vivo'.

A profecia joaquimita, na interpretação de alguns franciscanos espirituais, vai indicar dois personagens, um religioso e um político; e, algumas vezes, duas ordens monásticas, que protagonizariam os tempos da consumação do estado filial e início do estado espiritual. Para Vieira, seriam dois instrumentos - um eclesiástico e outro secular, um sumo pontífice e um imperador, um espiritual e outro temporal -, que operariam conjuntamente no período de consumação do Reino de 
Cristo. Ele menciona expressamente as figuras de um Pontífice Universal, um Pastor angélico, e um Novo guia político universal, o Imperador dos Últimos Dias (VIEIRA, 2000, p. 557). E, tal como o prognóstico de Joaquim, os dois personagens operariam no final do Reino de Cristo. Porém, diferentemente do abade de Fiore e também dos espirituais franciscanos do século XIII e seguintes, a consumação do Reino de Cristo não mais ocorreria na quadragésima segunda geração da igreja, isto é, nas gerações que compreendem o ano 1260, mas na segunda metade do século XVII, por volta de 1666. Aliás, o número 1666 será um número emblemático para Vieira, assim como foi o 1260 para o joaquimismo, pois, nele, completar-se-ia o "conto cheio" ou a "era do seis" dos prognósticos de Bandarra. Para Vieira, o "conto cheio" resultava da cifra formada por todas as letras utilizadas pelos numerais romanos, a saber: 1666 = M.D.C.L.X.V.I. (VIEIRA, 1957, t. 2, p. 26061). Além de ser uma espécie de número perfeito, um cômputo que utiliza todos os números romanos, um cálculo completo, estava formado por três números seis, remetendo ao conhecido número da Besta no Apocalipse. A explicação para a mudança desta escatologia nas mãos de Vieira decorre de um fato histórico: as novas descobertas e a necessidade de catequisar os indígenas. Com a descoberta do Novo Mundo e o programa de conquista espiritual de seus habitantes, reabre a questão da espera pelos tempos do fim, pois entre as tarefas que antecederiam a segunda vinda de Cristo, estava aquela de pregar o evangelho a todos os povos.

Mais uma vez, de outro modo que no joaquimismo, a realização das figuras escatológicas do Pastor angélico e do Imperador dos últimos dias fica limitada ao período previsto para o Reino de Cristo, e não há qualquer menção ao novo Reino espiritual. Tampouco estas figuras decorrem de uma hermenêutica por concórdia dos testamentos bíblicos; e, por isso mesmo, tais figuras não são a repetição em três estados de personagens e de contextos históricos, tal como no joaquimismo.

Passemos agora ao último ponto proposto, que tem como objetivo mostrar a permanência do núcleo do pensamento joaquimita e vieiriano numa obra de nossa literatura mais recente.

\section{Joaquim e Vieira na nossa literatura}

Publicado em 1971, O Romance d'A Pedra do Reino e o príncipe do sangue do vai-e-volta (1995), do escritor brasileiro Ariano Suassuna, já está em sua décima sétima (ROSSATTO; DE MARTINI, 2014). Recentemente, com base neste romance, a Rede Globo de Televisão produziu e exibiu, entre os dias 12 e 16 de junho de 2007, a minissérie $A$ Pedra do Reino, sob a direção de Luiz Fernando Carvalho. ${ }^{1}$

Nosso propósito é analisar alguns passos do capítulo inicial e do capítulo final, pois eles nos remetem ao cenário de abertura e de fechamento da trama da obra.

A cena que abre o romance é uma grande "cavalgada" que ocorre na véspera da festa de Pentecostes, o que situa o enredo do romance no interior de uma celebração dedicada ao Divino Espírito Santo (SUASSUNA, 1995, p. 35). O autor adverte, de saída, para duas peculiaridades desta cavalgada. A primeira delas é que aquele episódio, tal como se os personagens transitassem livremente das páginas da ficção literária e do repertório popular para o vivo palco da história, já havia sido previsto por um brasileiro "alumiado" e "visionário": o poeta indianista Gonçalves Dias (1823-1864), que vivera um século antes. A segunda peculiaridade é que a cavalgada estava sendo conduzida por três homens que levavam os estandartes da cerimônia. O primeiro está montado em um cavalo e conduz uma bandeira com três onças ver-

\footnotetext{
1 Sobre a minissérie brasileira da Rede Globo de Televisão, está disponível em: $\langle$ http://pt.wikipedia.org/wiki/A_Pedra_do_Reino $>$.
} 
melhas. Logo atrás vem o segundo homem, andando a pé, com uma cruz de madeira com aves de rapinas. O terceiro homem está montado em um cavalo branco e é designado como um Monge-Cavaleiro. Seu nome é Frei Simão. Ele empunha uma bandeira em que reluz um sol com seus raios em meio a um campo vermelho; e no centro do sol, temos um pombo branco voando. Segundo o autor, estamos diante da tradicional bandeira do Divino Espírito Santo (SUASSUNA, 1995, p. 49).

De resto, é importante notar que a caracterização dos três protagonistas dessa cavalgada coincide com a doutrina e o simbolismo joaquimitas (SUASSUNA, 1995, 561). O primeiro homem, de igual modo que o primeiro estado do mundo, está simbolizado pela Onça, indicando o período paterno, vivido sob a lei e em um regime em que se sobressai a força, a violência, a guerra, a atrocidade, a servidão e o temor. O segundo homem, caracterizado pelo símbolo da cruz com as aves de rapina (Gaviões e Carcarás), remete ao segundo estado, o estado filial, protagonizado por Cristo crucificado, e decorrido sob a lei e a graça, a servidão e a liberdade, a carne e o espírito. Segundo Joaquim de Fiore, em seu Liber introductorius in Apocalypsis (1964c, f. 5c), o primeiro dos três estados havia transcorrido sob a lei; o segundo, sob a letra do Evangelho; e o terceiro na plena liberdade do espírito. E, mais claramente, o terceiro estado espiritual está personificado por um monge, frade ou frei, em pleno acordo com a terceira era joaquimita - posteriormente propagada pelos freis franciscanos - em que os monges serão os protagonistas. Lembremos que os designativos "frei" e "frade" remetem igualmente à ordem franciscana. Por último, o terceiro personagem empunha a bandeira do Divino Espírito Santo em sua tradicional cor vermelha que, por si só, segundo a tradição luso-brasileira, já é uma clara alusão à celebração joaquimita do terceiro estado espiritual.

No penúltimo capítulo de A Pedra do Reino (Folheto LXXXIV: "O enviado do Divino"), encontramos duas passagens paradigmáticas em que a tarefa ou missão de um dos protagonistas do romance que, como observa o próprio autor, é o "motivo e honra" de toda a cavalgada, poderá ser lida em chave joaquimita (SUASSUNA, 1995, p. 45). O jovem Príncipe -"Prinspe", como quer o autor, remetendo a uma grafia popularizada nas ilustrações dos foIhetos de cordéis -, o Santo do cavalo branco é o enviado do Divino Espírito Santo que vai comandar a guerra do Terceiro Reino, o Reino do Espírito. Nestas duas passagens do romance, a nosso ver, ganham igualmente destaque os três estados (status), cada um deles comandados por uma das figuras da Trindade - a figura do Pai, a do Filho e a do Espírito Santo -, e estas figuras desempenham o mesmo papel designado na tradição joaquimita.

Para Joaquim, o Pai, ao longo do Antigo Testamento, se mostra um Deus terrível e cruel, caracterizando-se pelo uso da força, da guerra e da escravidão; o Filho, ao longo do Novo Testamento, se mostra como um Deus mais ameno, que prega o amor, a redenção, o perdão e a graça; e o Espírito Santo, coroando esta sequência, viria instaurar um novo período de graça plena e de liberdade espiritual. Em uma das passagens bastante conhecida da Concordia, Joaquim (1964b, f. 112a) assinala que o primeiro estado está caracterizado pela sujeição à lei, pela escravidão, pelo temor; o segundo se caracteriza pela graça e a servidão filial; e o terceiro, por sua vez, pela graça ampliada, a liberdade plena e a caridade.

Semelhantes características podem ser encontradas nesta outra passagem de A Pedra do Reino:

O Pai veio para criar, para castigar e expulsar. O Filho veio para remir e perdoar. O Espírito Santo vem para reinar e iluminar! O Reino do Pai se encerrou, e já estamos chegando ao fim do Reino do Filho. Vai começar o Reino do Espírito Santo, e ai daquele que for encontrado com mancha de pecado no sangue (SUASSUNA, 1995, p. 725). 
A segunda passagem a destacar nos faz ver que, em resposta à sequência de perguntas, temos a mesma caracterização dos três estados do mundo, e que o terceiro reino é o Reino do Espírito:

Seu Frade, me desculpe eu perguntar, mas a gente precisa saber, pra se garantir!" - gritou, perto de nós, o Cantador caolho, Lino Pedra-Verde. - "O Senhor é Frei Simão, o frade santo da Serra do Rodeador e da Pedra do Reino? O Rapaz que veio com o senhor é o nosso Prinspe, o Santo-do-cavalo-branco, que vem comandar os Sertanejos para a nossa Guerra do Reino? É verdade que ele veio para vingar o Pai, provar que é o Filho e, ao mesmo tempo, trazer o fogo do Espírito Santo para acabar com as injustiças e os sofrimentos do mundo (1995, p. 726).

Nesta segunda passagem, aparece um elemento novo que serve para indicar uma das possíveis soluções ao enigma proposto nas páginas iniciais do romance, depois da súbita reaparição do "perigoso" e "misterioso" rapaz-do-cavalo-branco, Sinésio Sebastião: ele seria o próprio enviado do Divino. E viria para reparar todos os males e injustiças cometidos, revelar-se como Filho e dar início ao tão esperado Reino do Espírito. No romance, há uma ambivalência montada estrategicamente que permite fazer a equivalência entre a história da vida pessoal do personagem principal, Sinésio Sebastião, e a história do mundo. A polissemia dos termos e a multiplicidade dos sentidos no relato, duas marcas características de toda a trama do romance, adquirem, enfim, uma unidade de significado e de sentido. O curioso é que aqui se torna possível obter um mesmo resultado mediante duas estratégias de leitura diferentes: a literal e a figurada.

De forma literal, temos o seguinte desfecho para a história. Sinésio Sebastião, que desaparecera no trágico dia em que seu Pai - o Rei do Quinto Império da Pedra do Reino, Dom Pedro Sebastião Garcia-Barreto - foi misteriosamente degolado, reaparece para vingar o próprio Pai (seu próprio pai), provar que é o Filho que havia desaparecido sem deixar vestígios; e enfim, sucedê-lo e comandar a guerra de conquista do novo reino, que é o Reino do Espírito.

A interpretação figurada (ou estética) é a seguinte: o rapaz-do-cavalo-branco de nome Sinésio Sebastião, assim como tantos outros que já havia desaparecido na Guerra do Reino (São Jorge, São Sebastião, Dom Sebastião, Antônio Conselheiro, Antônio Villar), ${ }^{2}$ volta em uma cavalgada triunfante para promover a vingança do Pai, tal qual a ação do Deus vingador do Antigo Testamento no primeiro estado joaquimita; provar que é o Filho ao reaparecer, "desencantar" ou "ressuscitar", levando a cabo o período referente ao segundo estado joaquimita; e finalmente, dar início ao novo Reino do Espírito.

Além disso, as duas passagens citadas são significativas para situar a "cavalgada" - que é o episódio inicial e final do romance - num interstício de tempo cronológico análogo ao que outrora se localizara a própria obra de Joaquim de Fiore ao final do século XII, a saber: no momento em que o Reino do Pai já havia chegado ao seu ocaso, o Reino do Filho estava vivendo os últimos episódios de sua fase de consumação, e o Reino do Espírito começava a colher seus primeiros frutos.

\section{Considerações finais}

No primeiro dos três pontos tratados, confirmamos o pressuposto de que a matriz do joaquimismo profético-utópico de corte luso-brasileiro está sedimentada nas tradicionais

\footnotetext{
${ }^{2}$ Antônio Villar é o nome usado por Luis Carlos Prestes (1898-1990) na clandestinidade. O tenente do exército e político Luís Carlos Prestes foi o principal líder comunista brasileiro do século XX. Foi casado com a judia-alemã Olga Benário que, mesmo grávida, foi deportada para a Alemanha nazista, onde morre na câmara de gás. Jorge Amado escreveu sua biografia no livro intitulado O cavaleiro da esperança (1942).
} 
Festas do Império do Divino Espírito Santo que ainda hoje ocorrem em diversas localidades de Portugal e do Brasil, especialmente nas antigas cidades do período colonial. Em tais festividades, tanto nas vestimentas dos personagens quanto na estrutura dos cultos, temos a manutenção do simbólica joaquimita. O simbolismo dos três estados se mantém intacto na memória de muitos de seus integrantes atuais. O clero, em geral, não participa da organização e da condução dos festejos, de acordo com o princípio joaquimita de que, no terceiro estado, a ordem clerical daria lugar à ordem monástica. Em muitos lugares, se mantém o antigo costume de coroar com três coroas, em que se sobressai ao centro um Imperador-Menino, secundado por um rei ancião e outro de meia idade. A literatura crítica é consensual ao apontar as festividades como uma verdadeira celebração do terceiro estado espiritual joaquimita. Com base nisso, concluímos que o horizonte utópico do joaquimismo permanece de forma constitutiva em uma das vertentes vivas da cultura brasileira que se manifesta sobretudo nas reivindicações populares em prol da justiça social, na resistência política e na luta por direitos. Exemplificamos com alguns movimentos populares que tinham em seu horizonte os resquícios da filosofia joaquimita, provenientes das Festas do Império do Divino e da obra profética do Padre Vieira.

Em segundo lugar, verificamos o pressuposto de que a vertente profético-milenarista, que se firmou - e ainda se mantém viva - na cultura brasileira, mesclada com o substrato joaquimita, apocalíptico, sebastianista e messiânico, se deve especialmente à obra profética do Padre Antônio Vieira. Embora pareça certo que o jesuíta não tenha bebido diretamente nos textos de Joaquim, já não se duvida a respeito de que essas ideias chegaram até ele mediante a literatura dos círculos franciscanos, além dos escritos proféticos de diferentes procedências e autorias, editados no período dos descobrimentos e da colonização do Brasil. De tudo isso, é possível que Vieira tenha assumido algumas ideias associadas a Joaquim pelos sebastianistas portugueses; e, em especial, ele dava por certo que o próprio Bandarra e alguns de seus divulgadores repetiam os ensinamentos do abade.

De modo inverso do que ocorre com o joaquimismo, os três estados vieirianos estão situados no interior do Quinto Império; e, além disso, estes mesmos estados fazem parte da divisão interna do Império de Cristo, sem qualquer projeção de um novo estado espiritual. No entanto, é possível que, mais tarde, Vieira retome a ideia de Quinto Império, tecendo-a com uma escatologia que remonta o horizonte do terceiro estado joaquimita.

De todos os casos, o que mais parece resistir ao teste da influência do joaquimismo na obra profética de Vieira é a utilização de duas figuras escatológicas, pouco comuns entre os jesuítas: a do Pastor angélico e a do Novo guia, nas figuras eclesiástica do Papa e política do Imperador dos Últimos dias. No entanto, essas figuras ainda estão limitadas ao Reino de Cristo, e não se aplicam ao Reino do Espírito.

Deste modo, a constituinte do mito fundador do Estado brasileiro, denominada como profético-milenarista joaquimita, que nos guiou desde o início pela mão de Marilena Chauí, a nosso ver, resulta do consórcio de duas tendências joaquimitas que influenciaram o pensamento brasileiro. A primeira é a vertente utópica que, como vimos, persiste nas celebrações e cultos ao Império do Divino Espírito Santo de tradição luso-brasileira; e a segunda é a vertente profético-milenarista, que resulta da obra profética de Antônio Vieira, a qual lança mão e mescla elementos de distintos matizes do substrato sebastianista, messiânico, apocalíptico e, inclusive, joaquimita. De resto, não há dúvida que a vertente profético-milenarista, incorporada pelas lutas populares, até hoje rivaliza com a visão providencialista agostiniana, que serve mais aos interesses da estrutura eclesiástica conservadora e das elites conservadoras.

Por fim, mostramos que o romance $A$ pedra do reino, de Ariano Suassuna, é um claro exemplo de que o pensamento joaquimita, presente na superfície mais visível de nossa cultura, 
e proveniente em larga medida das duas vertentes que colocamos em evidência, ganhará forma literária. Na narrativa de ficção, temos a presença das Festas do Império do Divino em toda sua rica costura simbólica, a teoria do Quinto Império e, de algum modo, a estrutura dos três estados joaquimitas. Não obstante, diferentemente do que ocorre na proposta de Vieira, o Quinto Império está associado com o primeiro estado joaquimita: o Pai é o Rei do Quinto Império, que fora destituído e degolado no início da trama. Por sua vez, o segundo e o terceiro estados ganham o protagonismo em uma alegoria semelhante à da celebração das Festas do Império do Divino, em muitos lugares realizada em conjunto com uma cavalgada que encena a luta entre mouros e cristãos. No entanto, como em Vieira, Suassuna acentua o messianismo ao dar centralidade à figura do Filho, o qual reaparece para fazer a Guerra do Reino e, com isso, vingar o Pai; mas, de qualquer modo, no final da trama prevalece a hermenêutica joaquimita, pois o objetivo maior dos personagens é instaurar o novo Reino do Espírito.

\section{Referências}

ADRIÃO, V. M. Mistérios iniciáticos do Rei do Mundo: História Oculta de Portugal. São Paulo: Madras, 2002.

ABREU, M. C. O império do divino: festas religiosas e cultura popular no Rio de Janeiro, 18301900. Rio de Janeiro/São Paulo: Nova Fronteira/Fapesp, 1999.

AURAS, M. A guerra do contestado. A organização da irmandade cabocla. Florianópolis: Editora da UFSC, 2001.

BANDARRA, G. E. Trovas. São Paulo: Iba Mendes Editor Digital, 2018.

BATAILLON, M. Evangelisme et millénaurisme au nouveau monde. Paris: PUF, 1959.

BESSELAAR, J. V. Antônio Vieira. Profecia e polêmica. Rio de Janeiro: EdUerj, 2002.

BERNAND, C.; GRUZINSKI, S. Histoire du Nouveau Monde: de la découverte à la conquête, une expérience européenne - 1492-1550. Paris: Librairie Arthème Fayard, 1991.

BITONTI, M.; OLIVERIO, S. Gioacchino: Abate di Fiore. San Giovanni in Fiore: Amministrazione Comunale di San Giovanni in Fiore/Centro Internazionale di Studi Gioachimiti, 1998.

BRANDÃO, C. R. O Divino, o Santo e a Senhora. Rio de Janeiro: Funarte,1978.

CHAUÍ, M. Brasil. Mito fundador e sociedade autoritária. São Paulo: Perseu Abramo, 2000.

CLETISON, J. Festas do Divino Espírito Santo. Núcleo de Estudos Açorianos (NEA) [Online]. Disponível em: http://www.nea.ufsc.br/artigos_joi.php. Acesso em: 11 dez. 2003.

CRISTÓBAL COLÓN. Libro de las profecías. Madrid: Alianza, 1992.

DE MARTINI, M.; ROSSATTO, N. D. Milenarismo na obra profética de Padre Antônio Vieira. Letras, Santa Maria, v. 21, n. 43, 2011.

ESPÍRITO SANTO, A. A Clavis Prophetarum à luz das referências intratextuais. Em: Martins, J.C.O. (Org.). Padre António Vieira. Braga: Publicações da Faculdade de Filosofia (UCP), 2009. p. 35-49.

FERNANDES, L. E. O. O franciscanismo espanhol em terras americanas: os irmãos menores na Nova-Espanha do século XVI. Revista Aulas, n. 4, abr./jul. 2007. p. 1-27.

FILATOW, F. Religião e política: o caso dos monges barbudos. 1935-1938). Métis: história e cultura. Rio Grande do Sul, v. 2, n, 2, 2002. p. 53-74. 
FRANCO, J. E.; MOURÃO, J. A. A influência de Joaquim de Flora em Portugal e na Europa. Escritos de Natália Correia sobre a Utopia da Idade Feminina do Espírito Santo. Lisboa: Roma, 2005.

FRANCO, J. E. O Quinto Império como sonho de regeneração de Portugal e do mundo. Reflexão, v. 33, n. 93, 2015.

GANDRA, M. Joaquim de Fiore. Joaquimismo e esperança sebástica. Lisboa: Fundação Lusíada, 1999.

GATTO, A. Introdução: Joaquim de Fiore e os selos do Apocalipse. In: FIORE, Joaquim de. Os sete selos. De septem sigillis. Intr., trad. e notas de Alfredo Gatto, com ensaio de Andrea Tagliapietra. Porto: Edições Afrontamento, 2015.

HUJAWA, H. A. Movimento dos Monges Barbudos. Revista Esboços, v. 19, n. 28, Florianópolis, 2008. p. 151-168.

JOAQUIM DE FIORE. Psalterium decem chordarum, Venedig: 1527. Reprint Frankfurt: Minerva, 1964a.

JOAQUIM DE FIORE. Concordia Novi ac Veteris Testamenti. Venedig: 1519. Reprint Frankfurt: Minerva, 1964b.

JOAQUIM DE FIORE. Expositio in Apocalypsim. Liber introductorius in Apocapypsis. Venedig: 1527. Reprint Frankfurt: Minerva, 1964c.

JOAQUIM DE FIORE. Os sete selos. De septem sigillis. Intr., trad. e notas de Alfredo Gatto, com ensaio de Andrea Tagliapietra. Porto: Edições Afrontamento, 2015.

MARTINS, J. S. Fronteira. A degradação do outro nos confins do humano. São Paulo: Contexto, 2009.

MILHOU, A. El mesianismo joaquimita del círculo jesuíta de Francisco de Borja (1548-1550). In: Rusconi, R. (Org.). Storia e figure dell'Apocalisse fra '500 e '600. Roma: Viella, 1996. p. 203-223.

PESSOA, V. A. O misticismo, o saudosismo e o sebastianismo em "Mensagem" de Fernando Pessoa. Santarém: Clube dos Autores, 2015.

PHELAN, J. The millennial kingdom of the Franciscans in the New World. Berkeley/Los Angeles: University of California Press, 1970.

POTESTÁ, G. L. Gioacchino da Fiore. Milano: Edizioni San Paolo, 1999.

REAL, M. Nova teoria do sebastianismo. Alfragide: Publicações Dom Quixote, 1990.

REEVES, M.; HIRSCH-REICH, B. The "Figurae" of Joachim of Fiore. Oxford: Clarendon Press, 1972.

REEVES, M.; HIRSCH-REICH, B.; GOULD, W. Gioacchino da Fiore e il mito dell'Evangelo eterno nella cultura europea. Roma: Viella, 2000.

ROSSATTO, N. D. (Org.). O simbolismo das Festas do Divino Espírito Santo. Santa Maria: Ufsm; Fapergs, 2003.

ROSSATTO, N. D. L'Abate Gioacchino e la Festa del Divino: una celebrazione luso-brasiliana dell'Età dello Spirito. Florensia, Bollettino del Centro Internazionale di Studi Gioachimiti. San Giovanni in Fiore, n. 18/19, 2005.

ROSSATTO, N. D.; DE MARTINI, M. The utopia of the Divine in Luso-Brasilien Culture: Joachim of Fiore and Ariano Suassuna's A Pedra do Reino. Portuguese Literary \& Cultural Studies, 26, 2014. p. 142-160.

SERPA, E. A guerra do contestado (1912-1916). Florianópolis: Editora da UFSC, 1991.

TODOROV, T. La conquista de América. La cuestión del otro. México: Siglo XXI editores, 1987.

VERARDI, L. Gioacchino da Fiore - Il Protocollo di Anagni. Tradução e reedição do texto latino de H. Denifle, Protocol der Commission zu Anagni. Anno 1255. Cosenza: Orizzonti Meridionali, 1992. 
VIANNA, H. O Reino do imprevisível. Folha de São Paulo [Online], 2000. Disponível em: http:// www1.uol.com.br/fol/brasil500/dc_7_1.htm. Acesso em: 7 jul. 2004.

VIEIRA, Padre Antônio. Apologia das coisas profetizadas. Lisboa: Edições Cotovia, 1994.

VIEIRA, Padre Antônio. Defesa perante o Tribunal do Santo Ofício. Tomo I e II. Bahia: Universidade da Bahia, 1957.

VIEIRA, Padre Antônio. História do Futuro. Brasília: Casa da Moeda, 1982.

VIEIRA, Padre Antônio. Clavis Prophetarum. A chave dos profetas. Livro III. Tradução e edição crítica de Arnaldo Espírito Santo. Lisboa: Biblioteca Nacional, 2000.

VIEIRA, Padre Antônio. Esperanças de Portugal. In: BESSELAAR, J. V. Antônio Vieira. Profecia e polêmica. Rio de Janeiro: EdUerg, 2002. p. 41-108.

WEST, C. D.; ZIMDARS-SWARTS, S. Joachim of Fiore. A study in spiritual perception and history. Bloomington: Indiana University Press, 1983.

\section{Sobre o autor}

Noeli Dutra Rossatto

Doutor em História da Filosofia (Medieval) pela Universidade de Barcelona. Professor Titular do Departamento de Filosofia da Universidade Federal de Santa Maria (UFRS).

Recebido em: 09/06/2020.

Aprovado em: 10/08/2020.
Received: 09/06/2020.

Approved: 10/08/2020. 